\title{
Sequential Injection Analysis: A useful Analytical Tool in Drug Dissolution Testing
}

\author{
Paraskevas D. Tzanavaras* \\ Laboratory of Analytical Chemistry, Department of Chemistry, Aristotelian University of Thessaloniki, GR-54124 Thessaloniki, Greece
}

Sequential-injection analysis (SI) is considered to be the second generation of flow injection techniques and was initially developed by Ruzicka and Marshall [1,2] as an alternative sample-handling technique to the well-established Flow injection analysis (FI) [3-5]. As can be seen in a typical SI setup in Figure 1, the heart of a SI manifold is a multiposition selection valve. Fluids are manipulated within the manifold by means of a bi-directional pump. A holding coil is placed between the pump and the common port of the multiposition selection valve. The selection ports of the valve are reservoirs, detectors, pumps, reactors, separators, special cells, other manifolds etc. After aspiration of a discrete volume (zone) of sample into the holding coil via the sample line, the sample can be subjected to very complex physical and chemical pre-treatment in different ways within the SI manifold. SI offers great potential for sample handling because it is a bidirectional, stopped-flow sample-handling technique enabling the sample to be serially processed in the different modules connected to the selection valve by means of repetitive aspiration and delivery steps. The advantages of SI over FI are the following: a) SI makes use of a simpler manifold that can be employed for a larger range of analytical methods without (or minimal) alterations in its physical configuration; b) in SI, discrete volumes of sample and reagents are aspirated and their consumption is drastically reduced; c) the bidirectional and stopped-flow operation of SI provides great scope for pre-treatment of the sample. This last attribute of SI makes it ideally suited to clinical and biochemical applications for which sample pre-treatment is usually necessary prior to the actual analytical measurement (Figure 2).

Drug absorption after oral administration of a solid dosage form depends on the release of the active ingredient from the formulation, its dissolution under physiological conditions, and the permeability across
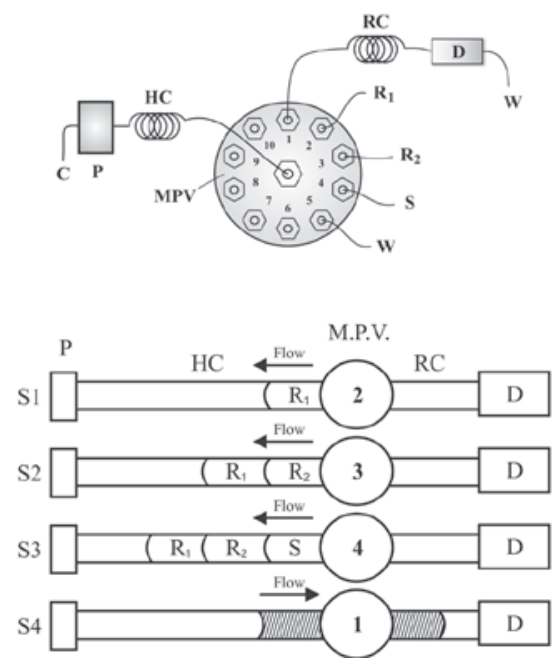

Figure 1: Typical SI setup and SI sequence steps: $P=$ pump; $C=$ carrier solution; $\mathrm{HC}=$ holding coil; MPV = multi-position valve; $\mathrm{RC}=$ reaction coil; $\mathrm{D}=$ detector; $\mathrm{W}=$ waste; $\mathrm{R}_{1} \& \mathrm{R}_{2}=$ reagents; $\mathrm{S}=$ sample; $\mathrm{S} 1-\mathrm{S} 4=\mathrm{SI}$ steps.

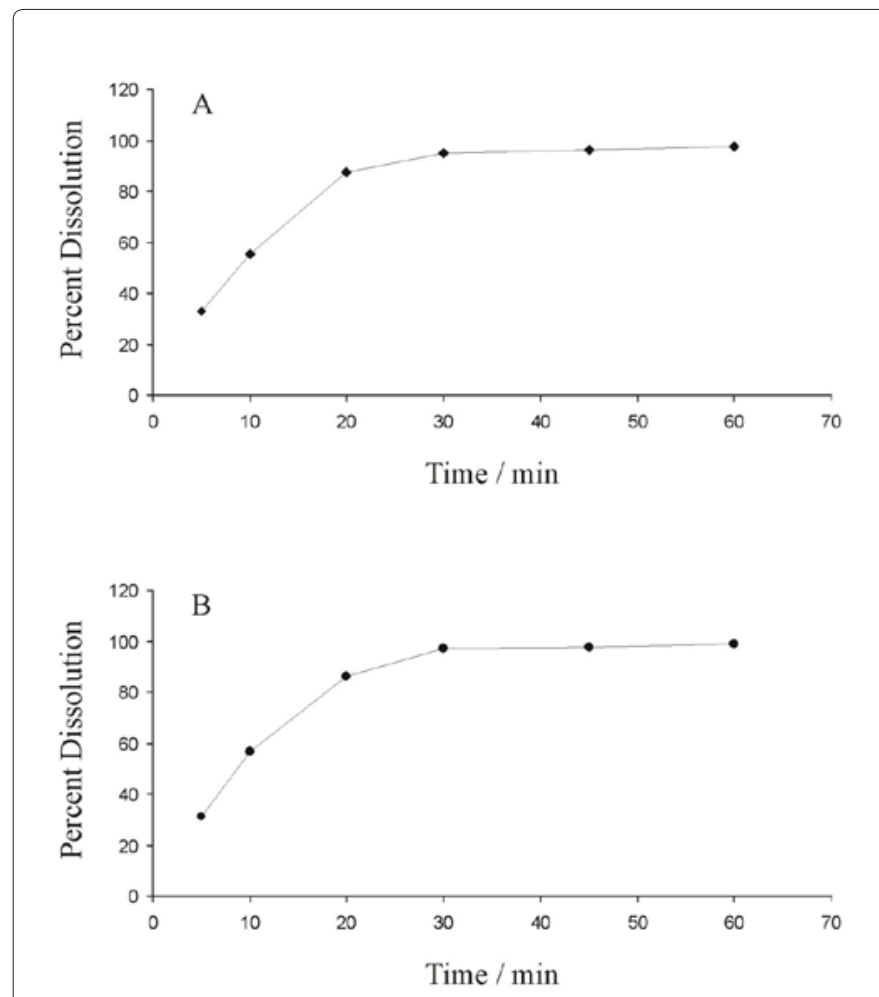

Figure 2: Comparative dissolution profiles of mexiletine formulations using $\mathrm{SI}$ (A) and HPLC (B) [14].

the gastrointestinal tract. Because of the critical nature of the first two of these steps, in vitro dissolution may be relevant to the prediction of in vivo performance [6-8]. It is therefore widely accepted that dissolution testing is a very important tool in the pharmaceutical industry for providing valuable information to both formulation teams that design new products and quality control scientists for ensuring lot-to-lot quality and consistency within pre-defined specification criteria $[9,10]$.

SI has proven a useful analytical tool for drug dissolution studies due to the enhanced automation capabilities and increased robustness of the

*Corresponding author: Paraskevas D. Tzanavaras, Laboratory of Analytical Chemistry, Department of Chemistry, Aristotelian University of Thessaloniki, GR54124 Thessaloniki, Greece, Tel: 0030 2310997721; E-mail: ptzanava@chem.auth.gr

Received July 07, 2012; Accepted July 09, 2012; Published July 13, 2012

Citation: Tzanavaras PD (2012) Sequential Injection Analysis: A useful Analytical Tool in Drug Dissolution Testing. Pharmaceut Anal Acta 3:e114. doi:10.4172/21532435.1000e114

Copyright: (c) 2012 Tzanavaras PD. This is an open-access article distributed under the terms of the Creative Commons Attribution License, which permits unrestricted use, distribution, and reproduction in any medium, provided the original author and source are credited. 
Citation: Tzanavaras PD (2012) Sequential Injection Analysis: A useful Analytical Tool in Drug Dissolution Testing. Pharmaceut Anal Acta 3:e114. doi:10.4172/2153-2435.1000e114

Page 2 of 2

\begin{tabular}{|c|c|c|c|c|c|}
\hline Analyte & Principle/Detection & LOD & Range & Sampling & Ref \\
\hline Indomethacin & $\begin{array}{l}\text { Reagent-free method based on photo-induced flurimetric } \\
\text { detection }(287 / 378 \mathrm{~nm})\end{array}$ & $1.2 \mu \mathrm{mol} \mathrm{L}{ }^{-1}$ & 4.1-90 $\mu \mathrm{mol} \mathrm{L}^{-1}$ & 20 & [11] \\
\hline Captopril & $\begin{array}{l}\text { On-line derivatization with methyl and butyl propiolate esters } \\
(285 \mathrm{~nm})\end{array}$ & $0.2 \mu \mathrm{mol} \mathrm{L}^{-1}$ & $10-220 \mu \mathrm{mol} \mathrm{L}-1$ & 40 & [12] \\
\hline Gemfibrozil & $\begin{array}{l}\text { On-line dilution based on zone-sampling by coupling of SI to fast } \\
\text { HPLC }\end{array}$ & $2.3 \mathrm{mg} \mathrm{L}^{-1}$ & $30-750 \mathrm{mg} \mathrm{L}^{-1}$ & 60 & [13] \\
\hline Mexiletine & $\begin{array}{l}\text { On-line derivatization by o-phthalaldehyde in the presence of } \\
\text { sulfite followed by fluorimetric detection }(350 / 446)\end{array}$ & $3.4 \mathrm{mg} \mathrm{L}^{-1}$ & $10-300 \mathrm{mg} \mathrm{L}^{-1}$ & 25 & [14] \\
\hline Propranolol & $\begin{array}{l}\text { Native fluorescence of propranol } \mathrm{HCl} \text { in Krebs-Ringer Buffer (ex: } \\
210 \mathrm{~nm})\end{array}$ & $0.02 \mathrm{mg} \mathrm{L}^{-1}$ & $0.2-80 \mathrm{mg} \mathrm{L}^{-1}$ & 60 & [15] \\
\hline Aminocaproic acid & $\begin{array}{l}\text { On-line derivatization by o-phthalaldehyde in the presence of } \\
\mathrm{N} \text {-acetylcysteine followed by fluorimetric detection }(350 / 450 \mathrm{~nm})\end{array}$ & $0.25 \mu \mathrm{mol} \mathrm{L}{ }^{-1}$ & $0-60 \mu \mathrm{mol} \mathrm{L}-1$ & $40-50$ & [16] \\
\hline Prazosin $\mathrm{HCl}$ & Native fluorescence of prazosin $\mathrm{HCl}(244 / 389 \mathrm{~nm})$ & $0.007 \mathrm{mg} \mathrm{L}^{-1}$ & $0.02-2.43 \mathrm{mg} \mathrm{L}^{-1}$ & 70 & [17] \\
\hline Ascorbic acid & Seperation by SI coupled to solid phase extraction & $10-100 \mathrm{mg} \mathrm{L}^{-1}$ & $1.0 \mathrm{mg} \mathrm{L}^{-1}$ & 26 & [18] \\
\hline Rutin trihydrate & Detection at $262 \mathrm{~nm}$. & $2-20 \mathrm{mg} \mathrm{L}^{-1}$ & $1.5 \mathrm{mg} \mathrm{L}^{-1}$ & & \\
\hline Ergotamine tartrate & Native fluorescence of Ergotamine $(236 / 390 \mathrm{~nm})$ & $0.01 \mathrm{mg} \mathrm{L}^{-1}$ & $0.03-0.61 \mathrm{mg} \mathrm{L}^{-1}$ & 120 & [19] \\
\hline Acetylsalicylic acid & Potentiometric detection by ion-selective electrode & $0.05 \mathrm{mmol} \mathrm{L}^{-1}$ & $0.05-10 \mathrm{mmol} \mathrm{L}^{-1}$ & 20 & [20] \\
\hline
\end{tabular}

Table 1: Applications of SI to drug dissolution studies.

technique under continuous operation. An overview of the published SI methods applied to the dissolution studies of pharmaceutical formulations for quality control purposes is presented in Table 1 [1122]. The active pharmaceutical ingredients are detected either directly by UV-Vis or Fluorescence spectroscopy, after suitable derivatization reactions or following HPLC separation. Automated sample treatment steps include - among others - dilution, filtration and on-line solid phase extraction. From the validation point of view, in contrast to assay methods, it is critical to evaluate the linearity from the LOQ e.g. $120 \%$ of the established level in order to obtain a dissolution profile. A common validation pitfall is the study of the specificity. Normally in SI methods applied to the QC of pharmaceuticals the selectivity is examined using either individual excipients or a suitable placebo. When the application of the method involves dissolution tests it is necessary to subject the spiked placebo mixture (synthetic samples) to the dissolution test as well under the exact same operating conditions.

\section{References}

1. Ruzicka J, Marshall GD (1990) Sequential injection: A new concept for chemica sensors, process analysis and laboratory assays. Anal Chim Acta 237: 329343.

2. Lenehan CE, Barnett NW, Lewis SW (2002) Sequential injection analysis. Analyst 127: 997-1020.

3. Ruzicka J, Hansen EH (1981) Flow Injection Analysis. Wiley and Sons: New York.

4. Hansen EH (2004) The impact of flow injection on modern chemical analysis: Has it fulfilled our expectations? And where are we going? Talanta 64: 10761083.

5. Smith JP, Hinson-Smith V (2002) Product review: Flow injection analysis Quietly pushing ahead. Anal Chem 74: 385A-388A.

6. Freitag G (2001) Guidelines on dissolution profile comparison. Drug Inform J 35: $865-874$

7. Tzanavaras PD, Verdoukas A, Balloma T (2006) Optimization and validation of a dissolution test for famotidine tablets using flow injection analysis. J Pharm Biomed Anal 41: 437-441.

8. Space JS, Opio AM, Nickerson B, Jiang H, Dumond M, et al. (2007) Validation of a dissolution method with HPLC analysis for lasofoxifene tartrate low dose tablets. J Pharm Biomed Anal 44: 1064-1071.

9. Food and Drug Administration: Guidance for Industry. Dissolution Testing of Immediate Release Solid Oral Dosage Forms (1997) US Department of Health and Human Services/Food and Drug Administration/Center for Drug Evaluation and Research, Rockville MD.
10. Siewert M, Dressman J, Brown CK, Shah VP (2003) FIP/AAPS guidelines for dissolution/in vitro release testing of novel/special dosage forms. Pharm Ind 65: 129-134.

11. Passos MLC, Saraiva MLMFS, Santos JLM, Reis S, Lúcio M, et al. (2011) A reagent-free method based on a photo-induced fluorimetry in a sequential injection system. Talanta 84: 1309-1313.

12. Tzanavaras PD, Tsiomlektsis A, Zacharis CK (2010) Derivatization of thiols under flow conditions using two commercially available propiolate esters. J Pharm Biomed Anal 53: 790-794.

13. Tzanavaras PD, Themelis DG, Rigas P (2009) Automated zone-sampling dilution by coupling sequential injection analysis to high-throughput HPLC for the direct determination of gemfibrozil. J Sep Sci 32: 2819-2826.

14. Tzanavaras PD, Zacharis CK, Rigas P (2008) Novel automated assay for the quality control of mexiletine hydrochloride formulations using sequential injection and on-line dilution. J Pharm Biomed Anal 48: 1254-1260.

15. Motz SA, Klimundová J, Schaefer UF, Balbach S, Eichinger T, et al. (2007) Automated measurement of permeation and dissolution of propranolol $\mathrm{HCl}$ tablets using sequential injection analysis. Anal Chim Acta 581: 174-180.

16. Pinto PCAG, Saraiva MLMFS, Santos JLM, Lima JLFC (2006) Fluorimetric determination of aminocaproic acid in pharmaceutical formulations using a sequential injection analysis system. Talanta 68: 857-862.

17. Legnerová Z, Huclová J, Thun R, Solich P (2004) Sensitive fluorimetric method based on sequential injection analysis technique used for dissolution studies and quality control of prazosin hydrochloride in tablets. J Pharm Biomed Ana 34: $115-121$

18. Legnerová Z, Šat'ınsky D, Solich P (2003) Using on-line solid phase extraction for simultaneous determination of ascorbic acid and rutin trihydrate by sequential injection analysis. Anal Chim Acta 497: 165-174.

19. Legnerová Z, Sklenářová $H$, Solich $P$ (2002) Automated sequential injection fluorimetric determination and dissolution studies of ergotamine tartrate in pharmaceuticals. Talanta 58: 1151-1155.

20. Paseková H, Sales MG, Montenegro MC, Araújo AN, Polášek M (2001) Potentiometric determination of acetylsalicylic acid by sequential injection analysis (SIA) using a tubular salicylate-selective electrode. J Pharm Biomed Anal 24: 1027-1036.

21. Liu X, Liu S, Wu J, Fang Z (1999) Simultaneous monitoring of aspirin phenacetin and caffeine in compound aspirin tablets using a sequential injection drug-dissolution testing system with partial least squares calibration. Anal Chim Acta 392: 273-281.

22. Liu X, Fang Z (1998) Sequential-injection system for drug-dissolution studies of ibuprofen tablets and sustained-release formulations. Anal Chim Acta 358: 103-110. 